\title{
REVISTA CIÊNCIA HOJE DAS CRIANÇAS: Uma Análise Documental Sobre Lixo, Coleta Seletiva e Reciclagem (2007-2016)
}

\author{
Danielle Cristina Duque Estrada Borim ${ }^{1}$ \\ Marcelo Borges Rocha
}

\begin{abstract}
RESUMO
Este artigo teve como objetivo investigar textos de divulgação científica publicados na revista Ciência Hoje das Crianças (CHC) relacionados à temática lixo, coleta seletiva e reciclagem, no período de 2007 a 2016. Foram encontrados 116 textos em que as palavras-chave aparecem entre os 110 fascículos analisados da revista. Foi possível observar que apesar de estarem relacionadas à área ambiental, as palavras-chave selecionadas para esta pesquisa transitam em diversas áreas, tornando-se assim um tema de cunho interdisciplinar. A revista estimula o hábito da leitura de seus leitores, traz uma grande variedade de sugestões de livros, além de filmes, peças de teatro e nos últimos anos, sites. Foram destacadas 63 menções de atividades lúdicas e experimentos que utilizam materiais recicláveis, as quais poderiam ser desenvolvidas em áreas diversificadas, tais como: Artes, Ecologia/Meio Ambiente, Física, Química, Nutrição, Zoologia, Música, o que demonstra mais uma vez o caráter interdisciplinar da publicação.
\end{abstract}

Palavras-chave: Divulgação científica. Mídia impressa. Educação ambiental. Ensino de Ciências.

CIÊNCIA HOJE DAS CRIANÇAS MAGAZINE:

A DOCUMENTARY ANALYSIS ON GARBAGE, SELECTIVE COLLECTION AND RECYCLING (2007-2016)

\begin{abstract}
The aim of this article was to investigate texts of scientific divulgation published in the magazine Ciência Hoje das Crianças (CHC) related to garbage, selective collection and recycling in the period from 2007 to 2016. There were 116 texts in which the keywords appear among the 110 issues analyzed from the journal. It was possible to observe that, although they are related to the environmental area, the keywords selected for this research are transposed in several areas, thus becoming an interdisciplinary theme. The magazine stimulates the habit of reading your readers, brings a wide variety of book suggestions, as well as movies, plays and in recent years, websites. A total of 63 mentions of recreational activities and experiments using recyclable materials, which could be developed in diversified areas, such as: Arts, Ecology / Environment, Physics, Chemistry, Nutrition, Zoology, Music, demonstrates once again the interdisciplinary nature of the journal.
\end{abstract}

Keywords: Scientific dissemination. Print media. Environmental education. Science Teaching.

RECEBIDO EM: 10/10/2017

ACEITO EM: 24/5/2018

\footnotetext{
${ }^{1}$ Doutoranda e mestre no Programa de Pós-Graduação em Ciência Tecnologia e Educação (PPCTE) do Centro Federal de Educação Tecnológica Celso Suckow da Fonseca - Cefet/RJ. Professora da rede pública municipal de Itaguaí (RJ). danideborim@yahoo.com.br

2 Doutor em Ciências Biológicas. Professor no Ensino Superior e no Programa de Pós-Graduação em Ciência, Tecnologia e Educação do Centro Federal de Educação Tecnológica Celso Suckow da Fonseca (Cefet/RJ). Coordenador do Laboratório de Divulgação Científica e Ensino de Ciências (Labdec). rochamarcelo36@yahoo.com.br
} 
A Divulgação Científica (DC) consiste no ato de tornar público, popularizar e/ou vulgarizar as ciências e seus avanços por meio de instrumentos e práticas sociais de comunicação, sobretudo os meios de comunicação de massa (VALÉRIO, 2005). Com isso, a DC é uma importante ferramenta para a socialização do conhecimento científico e a formação de uma população crítica em razão de diversos fatores, como um maior controle social sobre os impactos das atividades de Ciência e Tecnologia, a necessidade de ações para solução de problemas cotidianos e a crescente produção da ciência e sua complexidade (ISZLAJI et al., 2014).

Para Reis (2002, p. 76), um dos pioneiros em divulgar a Ciência no Brasil, a atividade de DC "é a veiculação em termos simples da Ciência como processo, dos princípios nela estabelecidos, das metodologias que emprega". Desta forma, mediante a DC os avanços científicos e tecnológicos podem chegar ao público leigo, assim como os processos e metodologias empregadas nela.

Nesse contexto, Rocha (2012) relata sobre a importância da compreensão pública da ciência, para que assim tenhamos uma sociedade democrática. Para isso, será necessário que aconteça um desenvolvimento cultural do povo, o qual terá de tomar conhecimento de pesquisas, experiências e preocupações científicas para almejar uma popularização da Ciência e da Tecnologia de fato.

Atualmente os meios de divulgar são os mais variados possíveis, como jornais, programas de televisão, documentários, revistas, rede de computadores (com o advento da Internet - blogs, canais de youtuber, sites, entre outros, o que dinamiza o processo de divulgação de informações e conhecimentos), centros e museus de Ciências, além de parques ecológicos e outros espaços não formais de ensino, os quais fazem da DC um campo vasto e de constante crescimento.

Segundo Fontanella e Meglhioratti (2013), essa variedade de meios de divulgação possibilita uma massificação dos assuntos relacionados à Ciência e à Tecnologia, porém as autoras destacam que nem todos estão preparados para lidar com as informações recebidas, o que torna essencial o letramento científico, principalmente na população escolar.

Destaca-se que Moreira (2006) alerta em seu trabalho, que apesar de todo o crescimento e reconhecimento da importância das atividades de DC no Brasil, ainda assim podemos encontrar amplas parcelas da população excluídas da educação científica e da informação qualificada sobre Ciência e Tecnologia, além de destacar a concentração dos centros e museus de Ciências em poucas regiões do país e a baixa frequência de visitantes desses locais.

Dessa forma, podemos observar que existe uma variedade de meios para se divulgar a ciência, entre eles a mídia impressa. Ao longo da História passamos pela oralidade dos anfiteatros, chegando à impressão dos primeiros artigos e o surgimento das primeiras revistas voltadas para a área, o que revela a grande importância da mídia impressa para todo o processo da DC. 


\section{DIVULGAÇÃO CIENTÍFICA NO ENSINO DE CIÊNCIAS}

De acordo com Nascimento e Souza (2005), a Ciência e a Tecnologia estão cada vez mais presentes no cotidiano do cidadão, seja por meio do contato direto com tecnologias e produtos ou ainda mediante o acesso às informações relativas a eles.

Dessa forma, podemos perceber mais uma vez a importância e a necessidade da democratização dos conhecimentos científicos e tecnológicos, para assim propiciar aos cidadãos uma melhor compreensão do mundo ao seu redor e assim intervir, de maneira consciente e responsável, em situações que impliquem a melhoria da qualidade de vida da sociedade (BORIM, 2015; VIECHENESKI; LORENZETTI; CARLETTO, 2012; AULER; DELIZOICOV, 2001).

Dentro desta perspectiva, podemos destacar a importância do ensino formal e, por conseguinte, da instituição de ensino. Nesse contexto está inserido o Ensino de Ciências, o qual possui como um dos seus objetivos a percepção e interação das relações entre conhecimento científico e tecnológico com a sociedade desenvolvido pela escola (BORIM, 2015). Da mesma forma que a própria história da Ciência e Tecnologia passou por transformações ao longo da evolução da humanidade, o Ensino de Ciências seguiu essas transformações, as quais se refletiram principalmente nos currículos de Ciências.

Segundo Krasilchik (2000), à medida que a Ciência e Tecnologia foram se tornando importantes para um melhor desenvolvimento econômico, cultural e social de uma sociedade, o Ensino de Ciências foi acompanhando esse crescimento, tornando-se objeto de diversos movimentos de transformações do ensino. Em seus trabalhos a autora traçou um panorama histórico sobre o Ensino de Ciências no Brasil de 1950 até 2000, em que podemos observar como as modificações políticas, econômicas e sociais de cada época, tanto no âmbito nacional quanto mundial, influenciaram as transformações das políticas educacionais.

Neste momento destacamos como a escola assume um importante papel dentro dessa perspectiva, ainda mais quando observamos os objetivos gerais do Ensino de Ciências descritos nos Parâmetros Curriculares Nacionais (PCNs) e também aqueles presentes nos Temas Transversais (BRASIL, 1998):

a) compreender a tecnologia como meio para suprir necessidades humanas, sabendo elaborar juízo sobre riscos e benefícios das práticas científico-tecnológicas;

b) compreender a natureza como um todo dinâmico, sendo o ser humano parte integrante e agente de transformações do mundo em que vive;

c) identificar relações entre conhecimento científico, produção de tecnologia e condições de vida, no mundo de hoje e em sua evolução histórica;

d) formular questões, diagnosticar e propor soluções para problemas reais a partir de elementos das Ciências Naturais, colocando em prática conceitos, procedimentos e atitudes desenvolvidos no aprendizado escolar;

e) valorizar o trabalho em grupo, sendo capaz de ação crítica e cooperativa para a construção coletiva do conhecimento;

f) compreender a tecnologia como meio para suprir necessidades humanas, distinguindo usos corretos e necessários daqueles prejudiciais ao equilíbrio da natureza e ao homem (p. 33). 
Desse modo, podemos compreender como o Ensino de Ciências aborda, de forma contextualizada, as competências de inserção da ciência e de suas tecnologias nos processos histórico, social e cultural. Além disso, reconhece e discute os aspectos práticos e éticos presentes na ciência do mundo contemporâneo (BRASIL, 2000).

Para atender à Lei de Diretrizes e Bases da Educação 9.394/96, a educação escolar vinculou-se mais ao mundo do trabalho e das práticas sociais, e o Ensino de Ciências passou a se dedicar à formação de um cidadão mais comprometido com as questões sociais relevantes ao mundo globalizado (SOUZA, 2013; KRASILCHIK, 2000). Isso posto, Viecheneski e Carletto (2011) concluem que as orientações dos PCNs estipulam que a formação do indivíduo cientificamente alfabetizado deva começar nos primeiros anos do Ensino Fundamental, já se aproximando ao enfoque CTS (Ciência, Tecnologia e Sociedade).

Sendo assim, a escola possui um papel significativo nesse processo, visto que ela, como parte integrante da sociedade, promove reflexões sobre mudanças políticas, econômicas, sociais e culturais que ocorrem nessa comunidade (ROCHA, 2012, 2010).

\section{A DIVULGAÇÃO CIENTÍFICA E A FORMAÇÃO DE UMA CONSCIÊNCIA AMBIENTAL}

Ao tentar atender aos objetivos de divulgar ciência, a sociedade começa a perceber que com os adventos científicos e tecnológicos trazidos pela Ciência e Tecnologia vieram junto, além de esperanças para os problemas vividos pela sociedade, também preocupações mundiais quanto ao futuro do homem no planeta, devido à degradação ambiental por eles ocasionada. A influência científico-tecnológica tão marcante nesse cenário acaba refletindo-se na educação, isso porque tem levado a uma abordagem educacional que privilegia a integração dos conteúdos científicos aos aspectos políticos, econômicos, sociais e ambientais, buscando de forma interdisciplinar formar esse aluno de modo crítico e atuante.

Segundo Santos e Mortimer (2002), o quadro de preocupação mundial acentuou-se nas últimas décadas, principalmente devido ao agravamento das questões ambientais e da frustração decorrentes dos excessos tecnológicos. Isso de certa forma propiciou um ambiente ideal para o surgimento da Educação Ambiental (EA) e das propostas CTS dentro do ensino, que surgem como consequência da necessidade de formar o cidadão em ciência e tecnologia, "o que não vinha sendo alcançado adequadamente pelo ensino convencional de ciências, desenvolvendo desta forma, a alfabetização científica dos cidadãos" (SANTOS; MORTIMER, 2002, p. 4).

Sendo assim, por intermédio de uma proposição de um Ensino de Ciências podemos auxiliar o aluno a construir conhecimentos, habilidades e valores necessários para tomar decisões responsáveis sobre questões inerentes à Ciência e à Tecnologia na sociedade, e atuar na solução de tais questões. Segundo Santos e Mortimer (2002), o objetivo central do ensino CTS é desenvolver a alfabetização científica e tecnológica dos cidadãos. Em complemento, Tozoni-Reis (2008) defende que essa alfabetização deve estar voltada para o desenvolvimento sustentável. 
Santos e Pereira (2012) observam que a perspectiva de CTS e de EA enfatizam a alfabetização científica dos alunos, fornecendo subsídios para que o Ensino de Ciências torne-se relevante para eles. Sendo assim, as disciplinas curriculares podem, além de propiciar o conhecimento dos fenômenos da natureza, desenvolver nos alunos a capacidade de se posicionarem em relação a problemas do mundo atual, buscando sempre que possível ter uma visão de sustentabilidade, tanto local quanto global.

Ainda nesse contexto, Santos e Mortimer (2002, p. 3) ressaltam que "não se trata de mostrar as maravilhas da ciência como a mídia já o faz, mas de disponibilizar as representações que permitam ao cidadão agir, tomar decisão e compreender o que está em jogo no discurso dos especialistas".

Por fim, Terrazzan (2000) menciona que as pesquisas desenvolvidas na área de Educação Ambiental indicam que para superar as dificuldades comuns aos docentes e estudantes, no âmbito escolar, podemos utilizar como ferramenta a DC, revelando-se ela capaz de proporcionar melhorias na qualidade do processo de ensino-aprendizagem.

\section{AS REVISTAS DE DIVULGAÇÃO CIENTÍFICA PARA O PÚBLICO INFANTOJUVENIL: O Caso da Ciência Hoje das Crianças}

A DC encontra diversos meios e ambientes para ser veiculada: Internet, televisão, rádio, jornais, revistas, no espaço escolar, nos museus, em espaços informais, porém sempre com a característica de ser uma atividade de difusão do conhecimento científico, voltada para fora do seu contexto original de produção e comunicação entre pares. Dessa forma, para se concretizar de modo eficaz é necessário o uso de diversos recursos e intervenções a fim de tornar aquele conhecimento atraente e compreensível para o público-alvo, que lê e não tem interesse pelo assunto (FRAGA; ROSA, 2015).

Segundo Gonçalves (2013), atualmente a mídia, seja no formato de jornais e revistas, seja no formato de programas de televisão e em sites da web, tem propiciado ao público leigo oportunidades de acompanhar os avanços da Ciência e da Tecnologia, podendo assim construir seu conhecimento. Entre os diversos veículos de divulgação da ciência, a mídia impressa é a mais antiga e utilizada ao longo dos tempos, considerada de grande importância comercial, estando frequentemente associada ao jornalismo científico (BARBOSA; AIRES; GONÇALVES, 2012; ALBAGLI, 1996).

Ao estudarmos a história da mídia impressa brasileira percebemos que ela evoluiu ao longo dos últimos dois séculos. As primeiras impressões em terras brasileiras ocorreram principalmente após a criação da Imprensa Régia, no início do século 19, imprimindo livros, jornais e revistas, além de manuais científicos. Surgem, então, os primeiros jornais que publicavam artigos e notícias relacionados à ciência, como o caso dos jornais Gazeta do Rio de Janeiro, O Patriota e o Correio Braziliense, este ainda editado em Londres (BORIM, 2015; MOREIRA; MASSARANI, 2002).

Vale destacar que o jornal $O$ Patriota foi o primeiro jornal dirigido ao conhecimento científico do país, circulando no Rio de Janeiro entre janeiro de 1813 e dezembro de 1814, sendo considerado um marco da DC no Brasil. Cobriu um extenso leque de assuntos científicos, desde informações sobre novos procedimentos agrícolas à Botânica, 
Medicina e Eletroquímica, passando pela cobertura de outros campos relacionados à ciência. Além disso, também abordava outros assuntos: política, Economia, Zoologia, Filosofia, Cartografia, Literatura, entre outros (KURY, 2011).

Apesar disso, o momento em que os periódicos relacionados à DC ganham mais espaço foi de 1850 a 1880. Na segunda metade do século 19, principalmente a partir de 1860, ocorreu um crescimento acentuado dessas publicações, o que demostra um relativo aumento de interesse pelos temas de ciência e a centralização da estrutura política e educacional, parte importante dos periódicos do Rio de Janeiro. É nesse período que surgem revistas como a Revista Brazileira - Jornal de Sciencias Letras e Artes (1857), Revista do Rio de Janeiro (1876), Ciência para o Povo (1881) e Revista do Observatório (1886), tendo destaque a Revista Brazileira - Jornal de Sciencias Letras e Artes, por ser a primeira a trazer contribuições significativas para a área, visto que dava grande ênfase aos assuntos científicos baseando-se tanto em artigos nacionais quanto internacionais (BORIM, 2015; BARBOSA; AIRES; GONÇALVES, 2012; MOREIRA; MASSARANI, 2002).

No início do século 20, com o surgimento de associações científicas, como a criação da Sociedade Brasileira de Ciências, em 1916 (importante marco para a DC nesse período) surgem diversas atividades que contribuem para o avanço da DC, entre elas a publicação de outras revistas, como a Revista Brasileira da Sociedade Brasileira de Ciências (1917), a Radio - Revista de Divulgação Científica Geral - especialmente consagrada à radiocultura (1923), a Revista Electron (1926), a Revista Sciencia e Educação (1929), todas com o intuito de divulgar a ciência, tendo destaque a Revista Sciencia e Educação, que tinha como objetivo divulgar a ciência de forma articulada com as questões educacionais (KEMPER, 2008; MOREIRA; MASSARANI, 2002).

Depois da Segunda Guerra Mundial os meios de comunicação, especialmente jornais, revistas e rádios, tornaram-se importantes canais de popularização da ciência no Brasil. Esse grande interesse pelas novas conquistas da ciência e busca por informações ocorreu devido à crença de que ela trazia possibilidades de soluções para o desenvolvimento do país (SILVA, 2007). Uma revista que ganha destaque nesta época é a Revista Ciência Popular, a qual circulou entre 1948 e 1966, com publicação mensal, editada no Brasil e tendo como objetivo realizar uma ligação entre a educação e a DC, tendo como público-alvo estudantes, profissionais e demais interessados na busca por conhecimentos mais amplos (idem).

Nas últimas décadas do século 20 surgem novas revistas de DC, entre elas a Superinteressante, Ciência Hoje e Globo Ciência (atual Galileu). Importante destacar que essas revistas têm enfoques bem diversos entre si sobre as formas de divulgar o conhecimento científico. Enquanto a revista Ciência Hoje, lançada em 1982 pela Sociedade Brasileira para o Progresso da Ciência, tinha uma preocupação maior com o que publicava e em atender aos objetivos da DC, a Superinteressante, em especial, tem menor preocupação quanto à qualidade e à dimensão crítica da ciência contida em seus artigos e textos, porém é mais acessível ao público em geral (MOREIRA; MASSARANI, 2002). 
Atualmente circulam no país diversas revistas voltadas para a DC, porém poucas são aquelas voltadas exclusivamente para falar de temas de ciência para o público infantil, sendo mais comum encontrar encartes ou ainda cadernos inseridos em jornais direcionados ao público adulto. Ainda assim, são poucos os jornais que possuem cadernos de ciências e suplementos correlacionados (FRAGA; ROSA, 2015; AIRES et al., 2003).

Logo, a criação da Revista Ciência Hoje das Crianças (CHC) é de grande significância e pode ser considerado um referencial para a consolidação da DC voltada para o público infantojuvenil. A CHC foi criada no ano de 1986, como uma iniciativa do Instituto Ciência Hoje (ICH), uma organização sem fins lucrativos vinculada à Sociedade Brasileira para o Progresso da Ciência (SBPC). A princípio a CHC surgiu na forma de um encarte dentro da revista Ciência Hoje, voltada para o público adulto (ALMEIDA; GIORDAN, 2014).

No ano de 1990 a CHC torna-se de fato uma revista independente, fruto do Projeto Ciência Hoje, responsável pelas publicações e produtos de DC da SBPC, tendo como público-alvo crianças de 7 a 14 anos. Com um caráter multidisciplinar, a revista CHC consegue abordar diversos temas "relativos às ciências humanas, exatas, biológicas, às geociências, ao meio ambiente, à saúde, às tecnologias e à cultura" (ALMEIDA, 2015, p. 4), por meio de 11 edições anuais (os meses de janeiro e fevereiro são editados em conjunto) e também do portal na Internet, Ciência Hoje das Crianças on-line (FRAGA; ROSA, 2015).

A revista $\mathrm{CHC}$ tem como objetivo promover a difusão do conhecimento científico e tecnológico por intermédio de suas publicações, as quais buscam aproximar cientistas, pesquisadores do público infantojuvenil, incentivando o fazer e o saber científicos, estimulando a curiosidade desse público ao mostrar que a ciência pode ser divertida e está ligada ao nosso cotidiano (AIRES et al., 2003; ALMEIDA; GIORDAN, 2014).

Para isso, a CHC apresenta um tratamento gráfico e editorial cuidadoso e diversificado, com uma agilidade de linguagem escrita e visual, de forma a tornar o conteúdo da revista atraente e acessível ao leitor. Os artigos científicos publicados por ela são escritos, em sua grande maioria, por pesquisadores nacionais, sendo eles enviados espontaneamente pelos seus autores ou ainda encomendados pelos membros da equipe editorial da revista, recebendo um tratamento jornalístico, mas sempre assinados pelos pesquisadores fornecedores daquela informação (ALMEIDA; GIORDAN, 2014).

Devido à revista $\mathrm{CHC}$ seguir os conteúdos presentes nos Parâmetros Curriculares Nacionais (PCNs), em 1991 passou a ser adquirida pelo Ministério da Educação e distribuída às escolas públicas de todo o país para ser utilizada como apoio em atividades desenvolvidas dentro da sala de aula (ALMEIDA, 2015; ALMEIDA; GIORDAN, 2014; RIBEIRO; KAWAMURA, 2011). Desta forma, ainda que a CHC não seja destinada para a sala de aula, ela constitui um importante recurso a ser utilizado pelos professores como um material alternativo de qualidade no apoio ao Ensino de Ciências na Educação Básica, assumindo assim também um caráter paradidático. Silva, Pimentel e Terrazzan (2011) completam mencionando que a sua distribuição pelas escolas públicas se dá também aliada a programas de apoio à leitura desse alunado. 
Além disso, a atuação do professor torna-se essencial para garantir o acesso a esse material por seus alunos, o que potencializa a democratização da ciência. Para isso é fundamental que este profissional esteja preparado para utilizar os textos de DC em sala de aula como um recurso alternativo.

Dessa forma, este artigo teve como objetivo realizar uma análise documental investigando os textos de divulgação científica publicados na revista Ciência Hoje das Crianças $(\mathrm{CHC})$, relacionados a temáticas ambientais (principalmente os que abordassem as palavras-chave lixo, coleta seletiva e reciclagem), no período de 2007 a 2016 . Os materiais encontrados foram averiguados sob os seguintes pontos: informações sobre os cientistas/pesquisadores/jornalistas (instituição a que pertence e formação acadêmica), e as principais características desses textos (a linguagem utilizada, uso de recursos como analogias, infográficos, metáforas, imagens, conceitos científicos, se há apelo inicial à leitura - impacto do título - recuperação de conhecimentos tácitos, presença de procedimentos explicativos, interlocução direta com o leitor e presença de narrativas).

\section{DESCRIÇÃO DO ESTUDO}

A pesquisa tem uma abordagem qualitativa, com caráter exploratório, e devido a sua complexidade foi dividida em fases. Na primeira fase realizou-se um levantamento dos artigos publicados na revista Ciência Hoje das Crianças que tinham como palavras-chave lixo, coleta seletiva e/ou reciclagem, dentro de um recorte temporal de 2007 a 2016, o que possibilitou uma maior atualidade e abrangência dos dados.

A escolha por essas palavras-chave deu-se pelo reconhecimento da importância da situação socioambiental pela qual a sociedade vem passando. Devido às atividades humanas, é inevitável a produção de resíduos, seja aquele oriundo do próprio processo produtivo, seja aquele produzido ao término da vida útil do produto. O consumo excessivo faz com que cada vez mais se produza lixo, e com isso a preocupação com o destino desse lixo torna-se um problema inerente a toda a sociedade (CORNIERI; FRACALANZA, 2010; MUCELIN; BELLINI, 2008).

Logo, ao investigar como a DC vem abordando as temáticas lixo, coleta seletiva e reciclagem em textos voltados para o público infanto-juvenil, podemos averiguar se estes podem ser utilizados dentro do ambiente escolar como uma ferramenta didática e ainda se contribuem para a formação de um indivíduo com consciência ambiental crítica e participativa.

Devido ao caráter exploratório e por envolver documentos escritos pela revista, optou-se pela análise documental, pois segundo Chaumier (1974 apud BARDIN, 1977, p. 45), é "uma operação, ou conjunto de operações visando representar o conteúdo de um documento sob uma forma diferente da original, a fim de facilitar sua consulta e referenciação".

Neste tipo de análise o pesquisador consegue avaliar a linguagem e o conteúdo presentes nos documentos sem ter interferência no objeto a ser estudado (SOUZA, 2013; KEMPER, 2008). A análise dos textos foi dividida em uma pré-análise e análise final. Ambas foram investigadas seguindo a metodologia da Análise de Conteúdo - AC 
(BARDIN, 1977). A escolha por essa metodologia deu-se por considerar que a AC tem como objetivo captar um saber que está por trás da superfície textual (ROCHA; DEUSDARÁ, 2005).

Segundo Bardin (1977), em um primeiro momento o pesquisador deve realizar uma organização da análise mediante uma primeira leitura dos textos produzidos, conhecida como leitura flutuante. Por meio desse tipo de leitura o pesquisador consegue extrair critérios de classificação dos resultados obtidos, possibilitando assim estabelecer categorias. Na sequência ocorre a codificação dos resultados com a formação das categorias de significação e por fim a informatização das comunicações.

Silva, Gobbi e Simão (2005) completam mencionando que a AC possui três fases fundamentais: a pré-análise (organização do material para que assim facilite a montagem do corpus da pesquisa); a exploração do material (quando o pesquisador cumpre decisões tomadas na fase anterior) e o tratamento dos resultados (em que o pesquisador, amparado nos resultados brutos, busca torná-los significativos e válidos).

Desta forma, pela análise documental o material coletado seguiu para uma pré-análise com a formação de categorias segundo a AC, em que após a leitura flutuante percebeu-se que os textos que apresentavam algo em comum poderiam ser agrupados nas seguintes categorias:

- Citações das palavras lixo, coleta seletiva, reciclagem

- Indicação de sites, livros, filmes e leituras complementares

- Atividades e experimentos

- Artigos completos

A categoria dos artigos completos devido a sua complexidade e riqueza em informações seguiu para uma análise aprofundada. Sendo assim, sofreu nova leitura flutuante - adotando ainda a metodologia de Bardin (1977), formando-se então subcategorias a fim de analisar os seguintes pontos: informações sobre os cientistas/pesquisadores/ jornalistas (instituição a que pertence e formação acadêmica) e as principais características desses textos (em qual contexto o artigo foi publicado, a linguagem do texto, uso de recursos como analogias, infográficos, metáforas, imagens, conceitos científicos, se há apelo inicial à leitura - impacto do título - recuperação de conhecimentos tácitos, presença de procedimentos explicativos, interlocução direta com o leitor e presença de narrativas).

- Sendo assim, as subcategorias formadas foram as seguintes:

- Apresentação do artigo

- Recuperação de conhecimento tácito e glossário

- Precisão científica

- Interlocução direta com o leitor

- Presença de analogias e metáforas

- Contextualização dos conhecimentos científicos 


\section{RESULTADOS E DISCUSSÕES}

Ao realizar esse levantamento foi encontrado um total de 116 textos em que as palavras-chave aparecem entre os 110 fascículos analisados da revista. Destes 116 textos analisados na pesquisa foi possível observar que: 63 deles sugeriam atividades e experimentos envolvendo principalmente materiais recicláveis; 31 traziam citações das palavras lixo, coleta seletiva e/ou reciclagem ao longo do texto; 11 indicavam site, livros, filmes e/ ou leituras complementares envolvendo alguma das palavras-chaves e 11 eram artigos completos que tinham como temática central lixo, coleta seletiva e/ou reciclagem.

Logo, os resultados observados seguindo a metodologia de AC (BARDIN, 1977) foram agrupados em categorias a serem apresentadas e discutidas a seguir:

\section{- Categoria 1: citações das palavras lixo, coleta seletiva, reciclagem}

Nesta categoria podemos observar que as palavras-chave são apenas citadas dentro de matérias ou atividades com temáticas diferentes, ou ainda não são artigos completos que tinham como temática alguma dessas palavras (lixo, reciclagem, coleta seletiva), ou seja, não constituem o foco central destes textos. Desta maneira, tivemos como resultado dentro desta categoria 31 materiais/reportagens com citações de lixo/ coleta seletiva/reciclagem, em que foi observado:

- A grande maioria das citações das palavras-chave ocorre em textos que envolvem a temática meio ambiente e ecologia. As palavras-chave aparecem em matérias que tratam sobre mudanças climáticas, bioindicadores, descarte correto de lâmpadas fluorescentes e pilhas, sugestões de preservação de florestas e do planeta, por exemplo. Destaque para a matéria que aborda o evento Rio+20, na qual entre as 20 ideias para salvar o planeta estão a coleta seletiva e a reciclagem.

- O cunho interdisciplinar da revista, visto que as citações das palavras-chave estiveram presentes em textos de áreas diferentes como Arqueologia/História, Desporto, Saúde e Zoologia, por exemplo, o que possibilita que os textos possam ser trabalhados dentro da sala de aula.

A característica de interdisciplinaridade da revista $\mathrm{CHC}$ foi também mencionada em outros estudos por outros autores. Quando mencionamos a interdisciplinaridade, tomamos como conceito o fato de ser colocada como um processo de articulação entre as disciplinas, ou seja, quando com o mesmo propósito um conjunto de disciplinas se junta para abordar um mesmo tema, de forma mais dinâmica, dando um significado ao saber escolar.

Logo, ao analisar outros estudos que utilizam a revista $\mathrm{CHC}$ como ferramenta ou recurso a ser adotado dentro da sala de aula, podemos perceber como essas pesquisas anteriores identificam esse contexto interdisciplinar da revista $\mathrm{CHC}$, a exemplo de Fraga e Rosa (2015), que ao realizarem uma investigação de textos de DC publicados na CHC relacionados à microbiologia, observaram que essa temática apareceu de forma atualizada e interdisciplinar nas matérias que abordavam microbiologia (relacionada a meio ambiente e questões sociais, econômicas e industriais). 
Outro estudo que aborda também essa característica é o de Ribeiro e Kawamura (2011), que expressam como essa variedade de abordagens presentes nos textos e artigos da CHC são fundamentais para o desenvolvimento de visões amplas durante o processo de construção do conhecimento científico. Segundo essas autoras, ao ter contato com um conteúdo de forma variada, possibilita-se que o aluno obtenha um enriquecimento das discussões, ampliando-se um leque nas relações que estabelece com o ensino formal (escolar) e o conhecimento informal.

Sendo assim, ao analisar o material coletado na pesquisa em questão, além de identificar o caráter interdisciplinar da revista $\mathrm{CHC}$ tomando como direção as palavras-chave lixo, coleta seletiva e reciclagem, também foi observada a forma atualizada com que esses conteúdos são apresentados ao leitor (a exemplo das reportagens sobre os eventos esportivos que aconteceriam no país e na cidade do Rio de Janeiro) e contextualizada (ao observar as reportagens que tratavam sobre o descarte correto das lâmpadas e pilhas).

\section{- Categoria 2: indicação de sites, livros, filmes e leituras complementares}

Esta categoria é formada pelas sugestões colocadas entre os 116 artigos/reportagens/matérias que possuíam alguma das palavras-chave lixo/coleta seletiva/reciclagem. Foram encontradas 11 sugestões de sites, livros e leituras complementares (não ocorreu sugestão de filme que tivesse o viés ligado a alguma das palavras-chave).

A grande maioria destas indicações estava na seção "Bate-papo" da revista, em que são apresentadas sugestões de livros, sites, filmes de diversos temas com uma pequena sinopse do material sugerido, a grande maioria voltada para o universo infantojuvenil, mas também havendo sugestões para toda a família e também para educadores. Logo, encontramos nos resultados nessa categoria:

- Seis indicações de livros abordando lixo, reciclagem, destaque para os que mencionavam em suas sinopses formas de desenvolvimento da consciência ambiental por meio do lúdico (exemplo dos livros "A casa do lixo zero", que trabalha a temática reciclagem, relembrando de uma forma diferente o conto infantil dos "Os 3 porquinhos", e o livro "Praia limpa é a minha praia", no qual destaca-se o fato de que os animais que moram na praia, revoltados com tanto lixo, tentam solucionar este problema) ou ainda com atividades criativas para preservação do planeta;

- Cinco sugestões de sites, três deles na seção $\mathrm{CHC}$ on-line, site da própria revista, e os outros dois estavam na sessão "Bate-papo" da revista. Entre o material sugerido estavam leituras complementares às reportagens da própria revista (como a da reportagem "Você sabia que existem ilhas de plástico" e sites com atividades lúdicas, como a elaboração de brinquedos utilizando material reciclável.

Por meio da análise desta categoria corrobora-se o perfil dado pela própria revista $\mathrm{CHC}$, de ser um meio de se divulgar ciência ao público infantojuvenil. Percebeu-se, também, que a revista estimula o hábito da leitura de seus usuários, principalmente quando se observa a seção "Bate-papo", a qual traz uma grande variedade de suges- 
tões de livros, além de filmes, peças de teatro e nos últimos anos, sites. Além disso, a sugestão de sites, inclusive ao indicar o próprio site da revista $\mathrm{CHC}$ para realizar uma leitura complementar sobre assuntos tratados na revista, é uma forma de se adequar à nova realidade e também de se incluir no universo virtual. O lado positivo dessa diferente ferramenta é que seria mais uma fonte para se obter informações no campo da ciência.

É importante destacar, porém, os cuidados necessários ao realizar essas buscas, as quais devem acontecer em sites que possuam informações confiáveis. Essa preocupação diminui quando a indicação desses sites está sendo feita por uma revista de DC, como a $\mathrm{CHC}$, trazendo um pouco mais de segurança ao que se é abordado.

\section{- Categoria 3: atividades e experimentos}

Nesta categoria foram analisados os materiais que traziam atividades lúdicas e experimentos apoiados nas palavras lixo, coleta seletiva e reciclagem (destacando-se que nessa última a questão do uso de materiais recicláveis foi considerada). Dessa forma foram encontradas 63 menções de atividades e experimentos, observando-se que:

- A maioria das atividades (66\%) tinha como ideia central utilizar material reciclável para realizar atividades lúdicas, a exemplo da confecção de brinquedos (como o mamulenco de garrafa PET e o bilboquê), instrumentos musicais (berimbalina - instrumento de corda) ou animais (joaninhas, porquinhos estilizados, centopeias de caixa de ovo, entre outros).

- As áreas disciplinares envolvidas nessas atividades e experimentos eram diversificadas: Artes, Ecologia/Meio Ambiente, Física, Química, Nutrição, Zoologia, Música, o que demonstra mais uma vez o caráter interdisciplinar da revista.

- Além de propor a atividade ou o experimento, foram encontradas também explicações do que estava sendo observado naquela atividade e/ou experimento, principalmente os que envolviam Física e Química.

- Aponte-se, nesta categoria, a flexibilidade das matérias e como a revista pode ser utilizada pelos professores dentro da sala de aula para abordar diferentes conteúdos de forma lúdica e informativa, uma vez que além de propor as atividades, existem em muitas delas propostas de explicações sobre o que pode ser observado durante tal atividade ou experimento. A presença desse tipo de material possibilita que o professor desenvolva atividades diferenciadas dentro do ambiente escolar. Aires et al. (2003) mencionam ainda a necessidade de o professor ter uma compreensão crítica ao usar os textos da $\mathrm{CHC}$ como instrumento pedagógico, tomando os cuidados relevantes.

\section{- Categoria 4: os artigos completos}

Nesta categoria foram encontrados 11 artigos completos, os quais possuíam como temática central as palavras-chaves lixo, coleta seletiva e/ou reciclagem (Quadro 1). 
Quadro 1 - Resumo das principais informações de cada artigo selecionado nas edições da revista Ciência Hoje das Crianças publicadas de 2007 a 2016

\begin{tabular}{|c|c|c|c|}
\hline $\begin{array}{c}\text { Código } \\
\text { do artigo }\end{array}$ & Título & Autores & $\begin{array}{c}\text { Edição e data de } \\
\text { publicação }\end{array}$ \\
\hline A1 & Você sabia que existe lixo no espaço? & Marcelo de Oliveira Souza & Edição 187/mar. 2008 \\
\hline A2 & O que é, o que é? & Breno Pannia Espósito & Edição 225/jul. 2011 \\
\hline A3 & Por que os animais marinhos comem lixo? & $\begin{array}{c}\text { Gustavo F. de Carvalho-Souza } \\
\text { Daniele de A. Miranda }\end{array}$ & Edição 232/mar. 2012 \\
\hline A4 & Por que o lixo é um problema de todos? & Jean Carlos Miranda & Edição 242/ jan./fev. 2013 \\
\hline A5 & $\begin{array}{c}\text { Como funciona a transformação de } \\
\text { garrafas PET em tecido? }\end{array}$ & Diego Fernandez & Edição 242/ jan./fev. 2013 \\
\hline A6 & Você sabia que existem ilhas de plástico? & João Paulo Machado Torres & Edição 252/dez. 2013 \\
\hline A7 & $\begin{array}{c}\text { Por que não devemos jogar lixo na areia } \\
\text { da praia? }\end{array}$ & Fabio Vieira de Araujo & Edição 255/abr. 2014 \\
\hline A8 & O lixo que é meu, é seu, é de todos nós & Marcelo Rocha & Edição 261/out. 2014 \\
\hline A9 & $\begin{array}{c}\text { Você sabia que o óleo que jogamos fora } \\
\text { pode ser reciclado? }\end{array}$ & $\begin{array}{c}\text { Marcelo Guerra Santos } \\
\text { Jaqueline Mulato da Silva }\end{array}$ & Edição 264/ jan./fev. 2015 \\
\hline A10 & E para o lixo, tudo ou nada? & Cristina Santos & Edição 274/nov. 2015 \\
\hline A11 & $\begin{array}{c}\text { Você sabia que a poluição da Baía de } \\
\text { Guanabara é também prejudicial para as } \\
\text { aves que retiram o alimento de lá? }\end{array}$ & Dayse Manhães & Edição 275/jan./fev. 2016 \\
\hline
\end{tabular}

Fonte: Os autores.

\section{- Subcategoria 1: Apresentação do artigo}

Neste momento foram analisados os seguintes pontos: quem escreve os artigos (formação e instituição vinculada), o impacto do título, o apelo inicial à leitura (forma de apresentação do texto - colunas, "boxes", as diferentes fontes, o tamanho do texto, a presença de imagens e ilustrações).

Para realizar a pesquisa sobre os autores foi usado como base o site da plataforma Lattes contendo o currículo fornecido por eles. As informações fornecidas por eles e que constam na revista $\mathrm{CHC}$ são insuficientes, fazendo assim que a busca pelo currículo Lattes fosse ainda mais necessária para avaliar a ação desses autores. Sendo assim, tivemos os seguintes resultados:

- Observou-se a existência de 13 autores (existem artigos escritos em parceria), 9 deles são do sexo masculino.

- A grande maioria (9 deles) dos autores faz parte de instituições localizadas na região Sudeste, não havendo representantes de instituições das regiões Norte e nem Centro-Oeste. Dois são de uma instituição do Nordeste (Universidade Federal da Bahia) e somente um vinculado a uma instituição da região Sul.

- Na análise quanto à formação acadêmica desses autores constatou-se que somente um deles é graduando, os outros ou possuem o grau de Doutoramento concluído ou no processo de Doutoramento.

- Quanto às áreas de formação desses autores, observamos que 9 deles possuem Graduação em Ciências Biológicas (com um ainda cursando a Graduação), um com formação em Licenciatura e Bacharelado em Física e outro com formação em Química. 
- Sete desses autores têm mais um ou outros artigos publicados na revista $\mathrm{CHC}$, além dos que são analisados na presente pesquisa. Destaque para dois desses autores que possuem, cada um, mais de dez artigos publicados na revista em questão.

- Um dos autores é uma escritora/bióloga com experiência em publicar livros voltados para o público infantil, e um segundo, além de constar como autor de um dos artigos estudados nessa pesquisa, também é mencionado como autor de um livro que é sugerido pela revista $\mathrm{CHC}$, ambos na mesma edição (sugestão que foi mencionada anteriormente na categoria sugestões de sites/livros e leituras complementares, livro "Praia limpa é a minha praia" - Fabio Araújo)

Analisando esses dados nota-se que a concentração de autores encontra-se na região Sudeste. Isso corrobora com o que alguns estudos utilizados como referenciais dessa pesquisa mencionam sobre a concentração de ações de divulgação científica estar entre as regiões Sudeste-Sul (MASSARANI, 2008; MOREIRA, 2006; MOREIRA; MASSARANI, 2002).

Além disso, ao pesquisar sobre a atuação acadêmica desses autores percebeu-se que todos eles escrevem sobre algo em que trabalham, tendo conhecimento de causa sobre o conteúdo exposto. Isso relembra um dos objetivos colocados pela divulgação científica, em que podemos ter especialistas escrevendo para o público geral de forma a aproximar esse leitor de conceitos antes restritos ao mundo científico, e demonstrando que esse mundo também faz parte do seu cotidiano.

Outro fator também relevante é que alguns desses autores desenvolvem projetos socioambientais que procuram alertar para as problemáticas ambientais, trazendo possíveis soluções para essas questões. Destaque para 3 desses autores que são coordenadores de projetos: um atuando como coordenador de um projeto sobre a poluição das praias, a segunda trabalhando com projeto de fotografias de monitoramento da Baía de Guanabara e o último trabalhando como coordenador de um projeto que envolve Educação Ambiental e Divulgação Científica.

O próximo ponto analisado dentro desta subcategoria é quanto ao impacto do título desses artigos. Dessa maneira, averiguou-se como cada título está apresentado, se ele é atrativo ao leitor, se possui correlação direta com o artigo que está intitulando, se se utiliza de recursos de expressão. Somente um dos títulos não é uma pergunta. Dos artigos selecionados para esta pesquisa, oito deles fazem parte de seções, as quais têm como características começarem com expressões comuns do público infantil feitas aos adultos (Por que, Você sabia, Como funciona). Na revista, essas expressões são acompanhadas do tema que vai ser abordado no artigo.

O uso de perguntas na apresentação de títulos é uma forma de estimular a curiosidade do leitor e fazer com que ele se motive a ler o artigo, para que assim possa descobrir a resposta desta pergunta inicial (inclusive um dos títulos é uma charada feita que atrai o leitor a descobrir "O que é, o que é"?). Sendo assim, essa pergunta surge como uma tentativa de estabelecer um diálogo entre o leitor e o autor do artigo, aproximando os mundos envolvidos, chamando-o para possíveis discussões (FREIRE; MASSARANI, 2012). 
Percebeu-se também que somente o título de um artigo não traz um indicativo da temática central que será abordado no texto a ser lido. Os outros 10 apresentam em seu título uma ideia do contexto ambiental que será tratado no artigo, e em seis deles a palavra-chave lixo está expressa no título.

O ponto seguinte analisado desta subcategoria é quanto ao apelo inicial à leitura dos artigos selecionados. Segundo Rosa e Fraga (2015), este ponto avalia quanto aos elementos que atraem ou prendem a atenção do leitor e o fazem querer explorar mais sobre a informação, chamando a sua atenção para a leitura. Nesse sentido verificou-se os seguintes pontos: a forma e tamanho dos textos, fontes utilizadas, presença de imagens e ilustrações. De certa maneira, estes pontos se complementam com o ponto analisado anteriormente. Desta forma, foi observado que:

- Quanto ao tamanho dos textos: oito são seções da revista CHC. Estas seções caracterizam-se por ocupar somente uma página da edição. No caso da seção "Como funciona", ela ocupa somente uma parte de uma página, oferecendo uma leitura bem dinâmica do material. Somente três artigos têm mais de uma página.

- Quanto à forma dos textos: são apresentados no formato de colunas com subtítulos em destaque (quando presentes). Quatro deles possuem boxe com informações complementares (o uso do recurso de recuperação do conhecimento tático ou de glossário, que pode se dar pelo uso de boxe, será discutido na subcategoria a seguir).

- Quanto ao uso de fotografias: seis dos textos continham fotografias (em dois deles existiam mais de uma fotografia), e em quatro deles, além desse material também havia ilustrações. Somente um artigo apresentava uma única fotografia (feita pela própria autora do texto) e nenhuma ilustração. Desta forma, totalizamos dez fotografias nesses seis textos, e somente em uma havia legenda explicativa. Apesar de não existir uma legenda nas outras fotos, podemos considerar que a compreensão não foi prejudicada, pois elas tinham inserção no contexto apresentado (por exemplo, em um dos textos, que aborda como podemos reciclar o óleo usado, havia fotos de comidas que utilizam óleo na fritura, junto com fotos de um rio e do planeta Terra, havendo uma correlação com o tema). Quanto aos créditos das fotos, cinco delas não possuíam o crédito ou fonte (quatro delas pertencentes a um mesmo texto).

- Quanto à presença de ilustrações: dez dos artigos analisados possuem pelo menos uma ilustração (sempre coloridas, conseguindo chamar a atenção do leitor e em alguns casos são ilustrações bem extensivas, ocupando mais de uma página). Todas as ilustrações expostas nas matérias, possuíam créditos e tinham relação com o texto abordado.

Ainda no contexto de ilustrações, observou-se que em duas delas há uma tentativa de demonstrar o ciclo do lixo e a reciclagem (no caso da garrafa PET que vira tecido de camisa), mas todas buscam, por meio do lúdico, aproximar o conteúdo do leitor, inclusive usando figuras com características humanas (em sete deles). Além disso, observamos também que os ilustradores utilizaram o antropomorfismo dos seres não humanos em algumas ilustrações. 
Os resultados obtidos vão ao encontro de resultados de outras pesquisas também realizadas com os textos de $\mathrm{DC}$ da revista $\mathrm{CHC}$, os quais mencionam que nos textos por eles analisados também foram encontradas imagens ilustrativas relacionadas com o tema abordado, além da presença de um apelo à leitura com textos atraentes e títulos chamativos, questionadores, bem como a presença de especialistas escrevendo para a revista CHC (FREITAS; MOREIRA; SILVA, 2016; FRAGA; ROSA, 2015; AIRES et al., 2003).

Segundo Zamboni (1997), os recursos utilizados no jornalismo científico são resultado da intersecção entre o discurso científico e o jornalístico, os quais tentam prender a atenção desse leitor primeiro pela manchete (um título atraente) e depois por intermédio de uma leitura dinâmica e rápida. Sendo assim, podemos concluir que dentro da categoria de apresentação dos artigos, todos eles utilizam-se de recursos a fim de estimular o interesse do leitor e buscam aproximar-se dele.

\section{- Subcategoria 2: Recuperação de conhecimento tácito e presença de glossário}

Nesta subcategoria foi observado se os artigos selecionados mostravam a presença de um conhecimento tácito ou de um glossário. O conhecimento tácito é aquele, segundo Zamboni (1997, p. 132), sobre o qual não cabe mais sujeitar à comprovação ou contestação, ou seja, é aquele conhecimento que já está internalizado, sendo comum a todos que fazem parte daquela área ou ainda um conhecimento implícito e comum. 0 termo "tácito" originou-se a partir do latim, significando "não expresso em palavras" ou "silencioso". Sendo assim, ao recuperar um conhecimento tácito ao longo de um artigo os autores buscam relembrar um conceito, apresentá-lo a um público leigo ou ainda configurar uma possível mudança de perspectiva sobre situações do cotidiano (FRAGA; ROSA, 2015).

Nesse contexto o uso de glossário é um recurso que os autores também podem utilizar para definições, conceituações ou referências que devem estar implícitas ao longo do artigo ou ainda presentes dentro de "boxes". A escolha pelo uso de "boxes" se dá para evitar que o texto fique "truncado", segundo Vieira (2007, p. 28).

Logo, foi observado que:

- Em todos os textos analisados foi detectada a recuperação de conhecimentos tácitos, o que demonstra uma preocupação da revista nesse momento, que pode ser o primeiro contato que aquele leitor tem com os assuntos abordados.

- Alguns deles apresentavam-se na forma de glossário, como é o caso da elucidação de termos como biodegradável, fotodegradável, diferença entre lixões e aterros sanitários. Essas elucidações, porém, apresentavam-se ao longo do texto, o que permite uma fluidez no conteúdo abordado. Um exemplo dessas explicações de termos aparece no artigo A8:

O trabalho de coleta seletiva em casa evita que os resíduos biodegradáveis - como restos de comida, cascas de frutas e verduras, entre outros - se misturem a outros materiais, podendo contaminar o solo, a água e atraiam animais que transmitem doenças (trecho do artigo - “O Lixo que é meu, é seu, é de todos nós”, p. 8). 
- Foi observada a ocorrência de boxe com informações sempre relacionadas ao conteúdo abordado, como o exemplo do artigo A4, o qual aborda "Por que o lixo é um problema de todos?". Ao mencionar o quantitativo de lixo produzido por nós, traz um boxe sobre o tempo de decomposição de cada material na natureza.

Nessa perspectiva, constatou-se ao analisar os textos dentro desta subcategoria que existe uma preocupação da revista em recuperar os conhecimentos, assim como de explicar conceitos e termos básicos das ciências ambientais. Ao fazer isso os autores procuraram mencionar tais termos e suas explicações ao longo dos textos, o que permite uma maior fluidez da leitura. Além disso, ao trazer situações cotidianas envolvendo essas explicações conseguem realizar uma aproximação com o mundo do leitor, fazendo com que ele se sinta parte integrante desse mundo científico.

Essas observações vão ao encontro do que foi observado nos trabalhos de outros autores. Apesar de buscarem por temas diferentes do ambiental em suas pesquisas, esses autores ao também analisaram os textos da revista $\mathrm{CHC}$, constataram a presença da recuperação de conhecimentos tácitos e conceitos ao longo da análise do material, corroborando assim para uma visão de preocupação da revista em transmitir as informações (FRAGA; ROSA, 2015; AIRES et al., 2003; GOUVÊA, 2000).

\section{- Subcategoria 3: Precisão científica}

Para esta subcategoria os artigos foram selecionados quanto à presença ou não de conceitos científicos e os procedimentos explicativos, assim como a existência ou não de erros conceituais.

A presença de procedimentos explicativos ao longo de um texto é uma forma de tornar claro os significados de termos técnico-científicos básicos, possibilitando assim uma aproximação e um direcionamento para o receptor leigo, o qual não está familiarizado com os conceitos científicos. Essa ação didática possibilita o compartilhamento do saber, o que fundamenta a divulgação científica (ZAMBONI, 1997). Ao realizarem essa explicação, porém, os autores devem ter o cuidado na transposição didática de termos científicos. Neste contexto, procurou-se observar também nesta subcategoria os possíveis erros conceituais presentes nos artigos selecionados.

Ao analisar os textos selecionados não foram observados erros conceituais. Isso deve-se talvez ao fato de que esses materiais sejam escritos por especialistas, indo ao encontro de Freitas, Moreira e Silva (2016) ao mencionarem quanto ao zelo da revista em manter fidelidade aos conteúdos abordados. Outro ponto também relacionado a esta visão é em relação à transposição didática dos conteúdos científicos. Mais uma vez notou-se o cuidado em realizar essa transposição didática de conceitos científicos pelos autores e equipe editorial da revista. Importante destacar, no entanto, que o mesmo não foi observado nos textos analisados por Aires et al (2003). Esses autores relatam que alguns dos textos analisados em suas pesquisas apresentaram defasagem em conceitos, o que, segundo eles, dificultaria ou até mesmo atrapalharia a compreensão de certos conteúdos relacionados à Física e Química. 
Nesse sentido, Gouvêa e Barros (2001) abordam as dificuldades encontradas quanto a essa transposição e o fato de deixar atraente o conteúdo científico a ser lido pelo público-alvo. Ao se apropriar da linguagem científica, a equipe editorial da revista deve também atuar de forma a fazer um trabalho em conjunto com os pesquisadores, desenvolvendo assim um texto de DC com uma linguagem específica, atraente a esse leitor. Desta maneira, conclui-se que a transposição didática para alguns conteúdos de Física e Química são mais difíceis de serem realizados com sucesso, devido à própria complexidade das áreas. Para a área ambiental já existe maior dinâmica e facilidade de a transposição didática acontecer, pois se trata de uma área com temas mais cotidianos e verossímeis ao leitor.

\section{- Subcatergoria 4: Interlocução direta com o leitor}

Neste momento foram averiguados os textos quanto à presença de interlocução direta com o leitor e as possíveis aparições de narrativas. A interlocução direta com o leitor ocorre quando há a presença de um diálogo entre o autor e o receptor, estabelecendo uma aproximação do último no processo de produção do texto, fazendo "compartilhar das mesmas apreciações" (ZAMBONI, 1997, p. 148).

Essa busca pela participação ativa do leitor pode acontecer por intermédio de perguntas diretas, sugestões colocadas, utilização de pronomes de tratamento, principalmente "você", ocorrendo assim um estreitamento de laços entre o autor e o leitor/ receptor (FRAGA; ROSA, 2015).

Dessa maneira, analisando os artigos selecionados tivemos como resultados:

- Entre os artigos analisados, somente um (o artigo A11) não tem o uso do pronome de tratamento "você". Este mesmo artigo não estabelece interação com o leitor. Existe somente uma pergunta no início dele, numa tentativa de recuperar um conhecimento tácito, e ao longo do texto há apenas uma explanação da situação em que se encontra a Baía de Guanabara e as aves que ali habitam, caracterizando assim um texto de divulgação científica para um público geral.

- Somente 2 dos 11 artigos não apresentam ou ainda mostram discreta interação com o leitor;

- Dez dos 11 artigos utilizam verbos de comando/ordem estimulando o pensar, participar, agir, colaborar, pesquisar mais sobre tal assunto, a fim de fazer com o que o leitor propague o conhecimento e ideais obtidos durante as leituras:

Pesquise no que mais os produtos que você conhece podem se transformar por meio da reciclagem. Investigue, colabore, alerte os amigos e você terá um planeta melhor para morar (trecho A2, p. 9).

Já vimos que reduzir o consumo é uma das principais maneiras de diminuir a quantidade de lixo. Você, leitor, estaria disposto a comprar menos pelo bem do ambiente? É hora de refletimos sobre isso... (trecho A8, p. 8).

- Ocorrência de textos com diversas interações com o leitor, por meio de perguntas, trazendo quadros do cotidiano para assim elucidar conceitos ambientais. Isso acontece principalmente nos artigos A2, A4, A6 e A8. 
Agora, vamos pensar: Qual será a origem do plástico? Desses plásticos mais comuns? Se você pensou petróleo, que dá origem a tantos produtos, como gasolina e o óleo diesel, saiba que você está redondamente certo! Sim, do petróleo também se obtém a nafta, que é a base do plástico (trecho A2, p. 7).

Você já deve ter visto algumas pessoas jogarem objetos, como papel e plástico, entre outros tipos de lixo, nas ruas públicas, em rios e nos terrenos baldios. Isso traz uma série de efeitos prejudiciais a todos nós (trecho A4, p. 18).

As sacolas plásticas que embalam suas compras podem ir parar no meio do oceano. É sério! Nessas áreas, elas (e outras embalagens similares) formam grandes ilhas de lixo...Você deve estar se perguntado como as sacolas podem viajar tanto (trechos A6, p. 12).

Sendo assim, conclui-se que, com exceção de dois artigos, todos os outros estabelecem grande interação com o leitor, havendo presença do pronome de tratamento "você", perguntas, verbos de comando, colocando situações do cotidiano. Esses resultados corroboram com o que Fraga e Rosa (2015) encontraram em seus estudos e com o que Zamboni (1997) menciona sobre essa interlocução ser uma forma de aproximação do leitor com o conteúdo abordado. Dessa forma ele, o leitor, pode sentir-se incluído no texto, estimulando o seu senso crítico e pensante, pontos favoráveis dentro dos objetivos da divulgação científica e da formação do cidadão consciente e atuante.

Além disso, ao mencionar ao leitor a ação de pesquisar mais sobre o assunto e difundir para outros sobre o que aprendeu, a revista contribui para uma formação de consciência ambiental, citada nos objetivos da Educação Ambiental.

\section{- Subcategoria 5: Presença de analogias e metáforas}

Nesta categoria procuramos observar e analisar a presença de analogias e metáforas nos artigos selecionados e se caso elas apareçam, qual o papel que desempenham no sentido de aproximar o leitor do conhecimento científico. Segundo Fraga e Rosa (2015), a analogia é uma comparação entre dois "conceitos/fenômenos/assuntos/ objetos, os quais possibilitam estabelecer uma relação, seja por semelhança, quer por diferença entre si" (p. 211).

Os textos de DC constantemente apresentam aos leitores termos novos, provenientes de um discurso científico (FRAGA; ROSA, 2015). Dessa maneira, a analogia é um recurso essencial no contexto da linguagem da DC, pois torna concretos conceitos abstratos, por permitir uma base de comparação ao leitor. Corroborando com essa visão, Silva, Pimentel e Terrazzan (2011) explicitam que mediante o uso das analogias pode-se construir um conhecimento científico, pois a sua utilização favorece a compreensão e o entendimento de conceitos que antes eram considerados difíceis para os alunos. É, no entanto, recomendado cautela, havendo um limite para essas analogias, evitando assim que o leitor as ultrapasse, e com isso tenha consequências desastrosas: "comparar coisas que são comparáveis" (VIEIRA, 2007, p. 18).

Juntamente com a analogia, a metáfora também é um recurso que podemos encontrar em textos de DC. Este recurso de linguagem é utilizado também em momentos de comparação empregado por semelhança real ou imaginária. De forma geral, podemos distinguir analogia de metáfora da seguinte forma: a metáfora é uma comparação implícita, enquanto a analogia é uma comparação explícita, mais complexa e elabora- 
da (DUARTE, 2005; BOZELLI; NARDI, 2005). Ambos são recursos utilizados para elucidar conceitos científicos de modo a aproximar o leitor da sua compreensão (SOUZA, 2013). Logo, dentro desta categoria foram observados poucos casos de analogias e metáforas nos textos analisados: somente 5 apresentam ( $A 4, A 5, A 6, A 7$ e $A$ 11), e somente um em cada texto:

Lembre-se de que a natureza leva muito tempo para decompor o que nós produzimos, portanto, não custa dar uma mãozinha (trecho A4, p. 18).

O resultado é uma fibra um pouco mais fina que a do algodão (trecho A5, p. 28).

Espalhe esse hábito por aí e mãos à obra (trecho A7, p. 12).

Ao analisar os casos de analogias e metáfora que apareceram nos textos selecionados para esta pesquisa, nenhum deles de fato tenta explicar algum conceito científico, mas tentam somente estimular a participação do leitor para contribuir com atitudes de melhora ambiental (caso dos A4 e A7), ou ainda para desmistificar a qualidade de um tecido que tem por base as garrafas PET, comparar o resultado final a um tipo de tecido conhecido como o algodão (como o caso do A5).

Dessa forma, concluiu-se que para as temáticas lixo, coleta seletiva e reciclagem, o uso de analogias e metáforas pela revista $\mathrm{CHC}$ é inexpressivo. Quando se compara os resultados dessa pesquisa com os de outros autores percebeu-se que a utilização de analogias e metáforas está mais presente em áreas que necessitam de uma maior abstração devido à complexidade, como é o caso das áreas de biomédica, biotecnologia, microbiologia. Ainda assim, no entanto, os resultados de diversos autores corroboram para o que se percebeu no presente estudo: que a revista $\mathrm{CHC}$ utiliza-se de poucas analogias e metáforas, inclusive para alguns casos em que seriam necessárias para uma melhor compreensão dos conceitos científicos abordados (FRAGA; ROSA, 2015; SILVA; PIMENTEL; TERRAZZAN, 2011; AIRES et al., 2003; SILVA; TERRAZZAN, 2003).

Outro ponto bastante observado dentro desta subcategoria, que por sua vez talvez esclareça a pouca ocorrência de analogias e metáforas para abordar temas ambientais, foi o fato de todos os artigos analisados dentro desta pesquisa possuírem uma linguagem muito clara, acessível, pela qual o leitor consegue assimilar o conteúdo, além disso estimulando a sua conscientização ambiental.

\section{- Subcategoria 6: Contextualização dos conhecimentos científicos}

Esta subcategoria avaliou a contextualização dos conhecimentos científicos apresentados nos artigos selecionados. Segundo Fraga e Rosa (2015), a contextualização possui diferentes significados, podendo se referir à realidade desse leitor. Sendo assim, podemos trazer ações do cotidiano desse leitor, as aplicações daqueles conceitos apresentados no seu dia a dia, e até mesmo estimular o exercício da cidadania, aproximando-o de conceitos da sociedade tecnológica, buscando compreendê-la criticamente e refletir sobre suas ações. Neste ponto mais uma vez podemos observar que os objetivos da Divulgação Científica estão presentes também dentro desta categoria.

Em todos os artigos foram observadas tentativas de contextualizar os conhecimentos científicos citando situações cotidianas, o que difere é a intensidade com que isso acontece em cada artigo. Por exemplo, no artigo A1 há uma menor contextualiza- 
ção, haja vista que se trata do lixo espacial, porém no final deste mesmo artigo há uma menção sobre o fato de que se não bastasse poluir o planeta Terra, também estamos poluindo o espaço.

Os outros dez artigos trazem situações cotidianas, aproximando aqueles conceitos e conhecimentos ambientais da realidade do autor, numa tentativa de mudança de hábitos com a conseguinte disseminação do conhecimento adquirido. Dessa forma, notou-se que os artigos analisados apresentam de forma representativa ações do cotidiano, as quais buscam a interação com o leitor, aproximando-se de sua realidade, para abordar alguns conceitos e ações ambientais. Ao fazerem referências a fenômenos rotineiros, conseguem de forma positiva explicar e elucidar essas situações dentro de uma perspectiva científica. Esse resultado legitima a concepção que Lopes (1999 apud FRAGA; ROSA, 2015) faz quanto ao uso dos saberes cotidianos para a compreensão do conhecimento científico, mencionando que apesar da dificuldade que pode haver para chegar a esse conhecimento científico ele pode ser dominado quando do uso do conhecimento cotidiano para chegar nele.

\section{CONSIDERAÇÕES FINAIS}

Após realizar a análise no material notou-se que apesar do número expressivo de 116 textos com os descritores, a quantidade de artigos completos que tinham como foco central essas palavras são pouco expressivos dentro do recorte temporal pesquisado, mais ainda levando em conta que a sociedade atual encontra-se com problemas nas reservas de recursos naturais e mesmo assim estimula-se o consumo. Nesta ótica, notou-se que a revista, por meio de seus textos, de forma lúdica e muito informativa, tenta estimular uma consciência ambiental e a participação de seus leitores para que também divulguem a ideia de conservação, consumo consciente e reciclagem de materiais.

Além disso, ao desenvolver artigos em parceria com pesquisadores, a $\mathrm{CHC}$ consegue manter o conteúdo fidedigno sem apresentar erros conceituais nos textos analisados. Complementando essa visão, o ato de especialistas escrevendo para o público leigo faz parte de um dos objetivos postos para a DC, o que possibilita uma aproximação do leitor a esses conceitos, antes restritos ao mundo científico, e demonstrando-lhe também que esse universo também faz parte do seu cotidiano. Aliado a isso ao realizar a transposição didática desses conceitos científicos tornam-nos mais claros e acessíveis ao público em geral.

Em relação ao cotidiano desse leitor, verificou-se que a $\mathrm{CHC}$ procura contextualizar os conhecimentos científicos apresentados em seus textos. Dessa forma, confirmou-se o que outros autores já haviam concluído em seus estudos, ou seja, a possibilidade de esses textos da CHC poderem ser trabalhados em sala de aula, como uma ferramenta didática para abordar diversos assuntos. Sendo assim, este artigo é parte integrante de um estudo maior que busca, além de analisar os materiais produzidos pela revista, desenvolver uma sequência didática para turmas do Ensino Fundamental em que o conteúdo abordado permeia os assuntos lixo, coleta seletiva e reciclagem, utilizando-se inclusive de alguns desses textos analisados e expostos no presente texto. 


\section{REFERÊNCIAS}

AIRES, J. A. et al. Divulgação científica na sala de aula: um estudo sobre a contribuição da revista Ciência Hoje das crianças. In: ENCONTRO NACIONAL DE PESQUISA EM EDUCAÇÃO EM CIÊNCIAS - ENPEC, 4., Atas... Bauru, SP: Enpec, 2003.

ALMEIDA, S. A. Cenas de leitura da Ciência Hoje das Crianças: modos de uso e apropriação da revista em sala de aula. In: REUNIÃO NACIONAL DA ANPED, 37., 2015, Florianópolis. Anais... Florianópolis: UFSC, 2015.

ALMEIDA, S. A. de; GIORDAN, M. A revista Ciência Hoje das Crianças no letramento escolar: a retextualização de artigos de divulgação científica. Educ. Pesqui., São Paulo, v. 40, n. 4, p. 999-1.014, out./dez. 2014. ALBAGLI, S. Divulgação científica: informação científica para a cidadania? Ci. Inf., Brasília, v. 25, n. 3, p. 396-404, set./dez. 1996.

AULER, D.; DELIZOICOV, D. Alfabetização científico-tecnológica para quê? Revista Ensaio - Pesquisa em Educação em Ciências, v. 3, n. 1, jun. 2001.

BARBOSA, G. A.; AIRES, J. A.; GONÇALVES, R. A linguagem na divulgação científica: uma análise da Revista Mundo Estranho. In: ENCONTRO NACIONAL DE ENSINO DE QUÍMICA, 16., 2012. Salvador, 2012.

BARDIN, L. Análise de conteúdo. Lisboa: Edições 70, 1977.

BORIM, D. C. D. E. Análise do potencial didático do livro de Fiç̧ão científica no ensino de ciências. Dissertação (Mestrado em Ciência Tecnologia e Educação) - Centro Federal de Educação Tecnológica Celso Suckow da Fonseca - Cefet, Rio de Janeiro, 2015.

BOZELLI, F. C.; NARDI, R. Interpretações sobre o conceito de metáforas e analogias presentes em licenciandos de Física. Enseñanza de las Ciencias, Barcelona, extra, 1-5, 2005.

BRASIL. Ministério da Educação. Parâmetros Curriculares Nacionais - Ensino Médio: Ciências da Natureza, Matemática e suas Tecnologias. Brasília: Secretaria de Educação Fundamental; MEC; SEF, 2000.

Ministério da Educação. Parâmetros Curriculares Nacionais: terceiro e quarto ciclos: apresentação dos temas transversais. Brasília: Secretaria de Educação Fundamental; MEC; SEF, 1998.

CORNIERI, M. G.; FRACALANZA, A. P. Desafios do lixo em nossa sociedade. Revista Brasileira de Ciências Ambientais, n. 16, jun. 2010.

DUARTE, M.C. Analogias na educação em ciências: contributos e desafios. Investigações em Ensino de Ciências, Porto Alegre, 10, 1, 2005.

FONTANELLA, D.; MEGLHIORATTI, F. A. A divulgação científica e o Ensino de Ciências: análise das pesquisas. In: ENCONTRO INTERNACIONAL DE PRODUÇÃO CIENTÍFICA, 7., Anais eletrônicos... Paraná: Cesumar, 2013.

FRAGA, F. B. F. F.; ROSA, R. T. D. Microbiologia na revista Ciência Hoje das Crianças: análise de textos de divulgação científica. Ciênc. Educ., Bauru, v. 21, n. 1, p. 199-218, 2015.

FREIRE, A. C. C.de M.; MASSARANI, L. A cobertura de ciência para crianças: um estudo de caso em dois jornais brasileiros. Alexandria, Revista de Educação em Ciência e Tecnologia, v. 5, n. 3, p. 101-126, 2012.

FREITAS, J. F.; MOREIRA, L. M.; SILVA, F. A. R; Análise do conteúdo de microbiologia presente na Revista Ciência Hoje das Crianças. Revista Ciências \& Ideias, v. 7, n. 1, 2016.

GONÇALVES, E. M. Os discursos da divulgação científica: um estudo de Revistas especializadas em divulgar ciência para o público leigo. Brazilian Journalism Research, v. 9, n. 2, 2013.

GOUVÊA, G., BARROS, H. L. B. Transformações do texto científico em texto de divulgação: o caso da Ciência Hoje das Crianças. In: ENCONTRO NACIONAL DE PESQUISA EM EDUCAÇÃO EM CIÊNCIAS, ABRAPEC, 3., 2001, Atibaia. Anais... Atibaia, SP: Abrapec, 2001.

GOUVÊA, G. A divulgação cientifica para crianças: o caso da Ciência Hoje das Crianças. 2000. Tese (Doutorado) - Universidade Federal do Rio de Janeiro, Rio de Janeiro, 2000.

ISZLAJI, C. et al. "Formando Jovens Divulgadores da Ciência, ações de alfabetização e divulgação científica”. In: ENCONTRO NACIONAL DE ENSINO DE BIOLOGIA (ENEBIO), 5., ENCONTRO REGIONAL DE ENSINO DE BIOLOGIA (EREBIO), 2. Revista da SBEnBio, São Paulo, n. 7, out. 2014.

KEMPER, A. A Evolução biológica e as revistas de divulgação científica: potencialidades e limitações para o uso em sala de aula. 2008. Dissertação (Mestrado em Educação) - Universidade de Brasília, UnB, Brasília, 2008.

KRASILCHIK, M. Reformas e realidade: o caso do ensino das ciências. São Paulo em Perspectiva, v. 14, n. 1, p. 85-93, 2000.

KURY, L. A Ciência útil em O Patriota (Rio de Janeiro, 1813-1814). Revista Brasileira de História da Ciência, Rio de Janeiro, v. 4, n. 2, p. 115-124, jul./dez. 2011.

MASSARANI, L. A divulgação científica: algumas considerações sobre o presente momento. ComCiência, Unicamp, v. 100, p. 1-100, 2008. 
MOREIRA, I. C. Communicating science and technology in Brazil: recent actions and attempts for establishing a national program. In: The 9th International Conference on Public Communication of Science and Technology. PCST Network Public Communication of Science and Technology. 2006. Disponível em: <https://www.pcst.co/archive/paper/1341>. Acesso em: 12 abr. 2017.

MOREIRA, I. de C.; MASSARANI, L. Aspectos históricos da divulgação científica no Brasil. In: MASSARANI, Luisa; MOREIRA, Ildeu de Castro; BRITO, Maria de Fátima (Org.). Ciência e público: caminhos da divulgação científica no Brasil. 1. ed. Rio de Janeiro: Casa da Ciência, 2002. p. 42-64. V. 43.

MUCELIN, C. A.; BELLINI, M. Lixo e impactos ambientais perceptíveis no ecossistema urbano. Sociedade \& Natureza, Uberlândia, v. 20, n. 1, p. 111-124, jun. 2008.

NASCIMENTO, T. G.; SOUZA, S. C. A produção sobre divulgação científica em eventos de Ensino de Ciências: vislumbrando tendências. In: ENCONTRO NACIONAL DE PESQUISA EM EDUCAÇÃO EM CIÊNCIAS (ENPEC), 5., 2005, Bauru. Anais... Bauru: Abrapec, 2005.

REIS, J. Ponto de vista. In.: MASSARANI, L.; MOREIRA, I. C.; BRITO, F. Ciência e público: caminhos da divulgação científica no Brasil. Rio de Janeiro: Casa da Ciência; UFRJ, 2002. 230p., p. 73-77.

RIBEIRO, R. A.; KAWAMURA, M. R. D. Divulgação científica para o público infantil: potencialidades da revista Ciência Hoje das crianças. In: SIMPÓSIO NACIONAL DE ENSINO DE FÍSICA, 19., 2011, Manaus. Anais... Manaus, AM, 2011. p. 1-14.

ROCHA, D.; DEUSDARÁ, B. Análise de conteúdo e análise de discurso: aproximações e afastamentos na (re)construção de uma trajetória. Alea, v. 7, n. 2, p. 305-322, 2005.

ROCHA, M. B. O potencial didático dos textos de divulgação científica segundo professores de ciências, R.B.E.C.T., v. 5, n. 2, maio/ago. 2012.

Textos de divulgação científica na sala de aula: a visão do professor de ciências. Revista Augustus, v. 14, n. 29, p. 24-34, 2010.

SANTOS, W. L. P.; MORTIMER, E. F. Uma análise de pressupostos teóricos da abordagem C-T-S no contexto da educação brasileira. Ensaio - Pesquisa em Educação em Ciências, v. 2, n. 2, 2002.

SANTOS, T. C. dos; PEREIRA, E. G. C. O enfoque CTS e a Educação Ambiental (EA) através de dinâmicas de grupo e aula-passeio: um estudo com licenciandos em Química. In: III ENCONTRO NACIONAL DE ENSINO DE CIÊNCIAS DA SAÚDE E DO AMBIENTE. Niterói-RJ. Anais..., 2012.

SILVA, C. C. O mundo científico ao alcance de todos: a revista Ciência Popular e a divulgação científica no Brasil (1948-1956). In: SIMPÓSIO NACIONAL DE HISTÓRIA, 24., 2007, São Leopoldo. Anais... São Leopoldo: Associação Nacional de História, ANPUH, 2007.

SILVA, C. R.; GOBBI, B. C.; SIMÃO, A. A. O uso da análise de discurso como ferramenta para uma pesquisa qualitativa: descrição e aplicação do método. Organizações Rurais \& Agroindustriais, v. 7, n. 1, p. 70-81, 2005.

SILVA, L. L.; PIMENTEL, N. L.; TERRAZZAN, E. As analogias na revista de divulgação científica Ciência Hoje das Crianças. Ciência \& Educação, Bauru, v. 17, n. 1, p. 163-181, 2011.

SILVA, L. L. da; TERRAZZAN, E. As analogias na divulgação cientifica: o caso da Ciência Hoje das Crianças. In: IV ENCONTRO NACIONAL DE PESQUISA EM EDUCAÇÃO EM CIÊNCIAS (ENPEC), 2003, Bauru. Anais... Bauru: ABRAPEC, 2003.

SOUZA, P. H. Análise da sistemática filogenética na Revista Scientific American Brasil. 2013. Dissertação (Mestrado em Ciência Tecnologia e Educação) - Centro Federal de Educação Tecnológica Celso Suckow da Fonseca - Cefet, Rio de Janeiro, 2013.

TERRAZZAN, E. A. Analogias no ensino de ciências: resultados e perspectivas. In: SEMINÁRIO DE PESQUISA EM EDUCAÇÃO DA REGIÃO SUL 3, 2000, Porto Alegre. Anais..., Porto Alegre, 2000.

TOZONI-REIS, M. F. de C. Educação ambiental: natureza, razão e história. Campinas-SP: Autores Associados, 2008.

VALÉRIO, M. "Os desafios da divulgação científica sob o olhar epistemológico de Gaston Bachelard". In: ENCONTRO NACIONAL DE PESQUISA EM EDUCAÇÃO EM CIÊNCIAS (Enpec), 5., 2005, Bauru. Anais... Bauru: Abrapec, 2005.

VIECHENESKI, J. P.; LORENZETTI, L. CARLETTO, M. R. Desafios e práticas para o ensino de ciências e alfabetização científica nos anos iniciais do Ensino Fundamental. Atos de Pesquisa em Educação - PPGE/ME, v. 7, n. 3, p. 853-876, set./dez. 2012.

VIECHENESKI, J. P.; CARLETTO, M. R. "Ensino de Ciências e Alfabetização Científica nos anos iniciais do Ensino Fundamental: um olhar sobre as escolas públicas de Carambei". In: Anais VIII ENCONTRO NACIONAL DE PESQUISA EM EDUCAÇÃO EM CIÊNCIAS (ENPEC), 8., CIEC - CONGRESO IBEROAMERICANO DE INVESTIGACIÓN EN ENSEÑANZA DE LAS CIENCIAS, 1., 2011, Campinas. Anais... Campinas, 2011.

VIEIRA, C. L. Pequeno manual de divulgação cientifica: dicas para cientistas e divulgadores de ciência. São Paulo: CCS; USP, 2007.

ZAMBONI, L. M. S. Heterogeneidade e subjetividade no discurso da divulgação científica. 1997. Tese (Doutorado em Linguística) - Universidade Estadual de Campinas, Campinas, SP, 1997. 